\title{
Managing the Company in the Setting of Implementing Large-Scale Development Programs
}

\author{
Nikolay Kuznetsov ${ }^{1}$ \\ ${ }^{1}$ Financial University under the Government of the Russian Federation, Moscow, Russia \\ Correspondence: Nikolay Kuznetsov, Financial University under the Government of the Russian Federation, \\ 125993, Moscow, Russia.
}

Received: September 23, 2014 Accepted: October 10, 2014 Online Published: December 2, 2014

doi:10.5539/ass.v11n1p193

URL: http://dx.doi.org/10.5539/ass.v11n1p193

\begin{abstract}
This article examines issues of streamlining project management systems in the setting of implementing large-scale company development programs.

The primary aim of this work is to present a methodological approach towards the development of specific functional areas of project management and the formation of a baseline plan for the implementation of the project, which consists of three major documents - a content management plan, a baseline schedule, and a project cost management plan. The work provides methods and algorithms for the formation of baseline plan results and qualitative and quantitative assessment of risks and the project budget.

At the same time, the author provides a number of limitations to the use of the proposed methodology, the most crucial of which deal with companies' lack of specialists possessing the necessary level of professional competencies, lack of special programming solutions on the automation of project management systems, and the labor intensity of accurate and full quantitative assessment of possible damage in case of a risk event arising.
\end{abstract}

Keywords: company management, project management, large-scale development programs, business plan

\section{Introduction}

Operating in an uncertain external environment, modern business is oriented towards continuous development which ensures companies a competitive edge in the market (Dvorakova \& Zborkova, 2014).

A mandatory condition for the company's sustainable development and competitiveness in the market is top-notch, effective management that combines a whole range of various aspects: organizational-managerial, technological, marketing, financial, investment, etc. (Binner, 2010).

As we know, the primary objective of executives keen on getting the company to continuously materialize its production, sales, and financial inflows, which are crucial to successful performance, is to make the company's product competitive. This objective is successfully resolved only by those companies whose executives manage to put together a management system that successfully materializes the major management functions, which are planning, organization, motivation, control, and ensures the effective implementation of the primary management cycle (Litvak, 2011).

In general terms, management is construed as a complex of interrelated, goal-oriented actions which ensure the maximum social-economic effect through the rational use of various types of resources and a shift towards a more enhanced state of the company (Blokhina et al., 2014).

One of the major conditions for the effective operation of the company in modern conditions is that the management system ought to keep getting streamlined - and that means it must change every now and then. It is known that as they grow and mature all companies go through progressive stages of development. These stages of growth possess specific distinctive characteristics, and in each stage there is the need for streamlining management, which ensures a successful shift to the next stage of development (Shimasaki, 2014).

Management is based on developing, to start with, an integrated model of actions aimed at attaining goals set and implemented through adopting company development projects or programs (Fidelman, 2012). 
Combining projects into large-scale development programs helps achieve a better quality of managing them, while projects themselves become one of the more efficient mechanisms for managing the company (Illarionov \& Klimenko, 2013).

The implementation of large-scale programs requires proper resource support (He, Chaudhary, \& Jarvis, 2014). When it comes to achieving the end-result of company development programs and ensuring the concentration of necessary resources, project management is regarded as the most preferable type of management (Mir \& Pinnington, 2014).

Various studies reveal that project management possesses a number of qualitative and quantitative advantages compared with any other approach to management (Lappe \& Spang, 2014). Since most companies have limited resources to invest, they select those projects which let them achieve major results in implementing their business-strategies (Amason, 2011).

However, approximately $60 \%$ of all companies undertaking development projects fail in actualizing their strategies, and their development programs do not yield expected results (Kaplan \& Norton, 2008).

The experience of actualizing large-scale company development programs indicates there a particular range of issues of a methodological nature which arise in managing resources (Zhang et al., 2014). This makes the streamlining of resource analysis especially topical.

\section{Methods}

The company's large-scale development program is developed as an integral aggregate of portfolios of projects of various types (innovation, technical, organizational, marketing, etc.), activities that ensure the attainment of necessary indicators of the efficiency of the company's activity, which are a combination of organizational, economic, marketing, technological, and other measures (Serra \& Kunc, 2014).

The project program is construed as a group of projects brought together with a view to achieving better management, reducing risks from projects, and boosting the economic efficacy of projects.

The primary instrument for the integration of participants in the project, which ensures that all the members of the project team get a better understanding of their objectives and responsibility, is the Project Management Plan.

In the Project Management Plan, one can provide a brief description of each area of knowledge and reference a detailed plan of managing a particular area of knowledge; one can also provide a detailed description in the primary Project Management Plan.

The project manager must, based on his experience, define the format and details of both the Project Management Plan and all auxiliary plans.

At the same time, the Project Management Plan must by all means contain Baseline Plans for three areas of knowledge - a content plan, a baseline schedule, and a baseline cost fulfillment plan. Combined, these baseline plans are called the Baseline Fulfillment Plan.

The Baseline Content Plan. For the project to be a success, the project manager, the project team, as well as all key interested persons (stockholders) ought to have a clear idea of the project's content, its purpose. The Baseline Content Plan is a document that describes what has to be done for the project to be considered a success. Since the document is for internal use, it can be executed in arbitrary form.

The Baseline Schedule. To achieve the maximum efficiency of their development programs, companies work out the project schedule, which enables them to arrange their resources and control the course of implementing the project.

Structural decomposition of project jobs, their description
Establishment of interrelations between jobs
establishment of times for the completion of the project as a whole
$\begin{aligned} & \text { Assessment of the need for resources for each type of jobs and subsequent adjustment } \\ & \text { of the plan inclusive of the resource deficit or reallocation of resources. }\end{aligned}$

Figure 1. An algorithm for the development of the project schedule 
The most common project resource arrangement method is calendar-network planning. Network models enable one to determine the probable duration of the implementation of jobs, their cost, the probable size of funds and time saved, as well as the "criticality" level of particular operations.

Jobs are called critical when delaying them can lead to failure to meet the deadlines for the entire project. The sequence of developing the project schedule is provided in Figure 1.

The first three stages make up the essence of network analysis, while the last one does that of calendar planning.

In the first stage, one develops the hierarchical structure of jobs, which will help resolve the following objectives:

1. Determine thanks to which types of jobs the goal set in the project will be achieved;

2. Check the fullness and correctness of setting the project goals;

3. Establish key criteria, which at a certain stage of detailing must be clearly designated in the network model and the calendar plan;

4. Appoint managers responsible for the attainment of key criteria;

5. Clearly designate the role of each member of the project team in the context of group work on the project.

A number of special models are used for structuring the project: the tree of goals, the tree of solutions, WBS, the matrix of responsibilities, network models, the structure of consumed resources or costs, etc.

In the second stage, one establishes interrelations between jobs in the project. There are three types of dependencies:

- Mandatory dependencies, which are physically inherent to jobs (for instance, it is impossible to install equipment before it is delivered).

- Dependencies at one's discretion, which are established by the project team in accordance with commonly accepted practice or with the preferences of the members of the project team. Such dependencies ought to be rigorously documented to avoid project deadline violations.

- External dependencies, which define interrelations between project and non-project works.

The third stage involves establishing the duration of jobs and times for the completion of the project as a whole. To assess the dates for the beginning and end of jobs, the critical path method (CPM) is used, which is based on mathematical analysis that helps establish early and late dates for carrying out specific jobs, as well as reserves of time which can absorb some of the work to prevent the violation of project completion deadlines.

The algorithm for establishing the critical path includes the following actions:

1. Establishing the earliest date for the beginning and the earliest date for the end of the implementation of a specific job. The time for the completion of a job is determined via the following formula:

$$
\mathrm{EF}=\mathrm{ES}+\mathrm{T}_{\text {operation }}
$$

where $\mathrm{EF}$ is a date earlier than on which it is impossible to complete a job, given the time for the completion of preceding operations;

ES is an early date of the beginning of a job;

$\mathrm{T}_{\text {operation }}$ is the duration of a job.

2. Establishing the latest date of the beginning and end of jobs via the following formula:

$$
\mathrm{LF}=\mathrm{LS}+\mathrm{T}_{\text {operation }}
$$

where LF is a date later than on which it is impossible to complete a job without delaying the implementation of the project;

LS is a date later than on which one cannot start a job without delaying the implementation of the project.

3. Critical operations are those for which early and late beginning and end times overlap, i.e.:

$$
\mathrm{ES}=\mathrm{LS} ; \mathrm{EF}=\mathrm{LF}
$$

The total duration of critical operations makes up the critical project path.

When it comes to calendar planning, special attention is given to establishing the time reserve, i.e. a period of time for which the job can be delayed without affecting the overall duration of the project.

$$
\mathrm{TF}=\mathrm{LET}_{\text {end }}-\mathrm{EET}_{\text {beginning }}-\mathrm{T}_{\text {operation }}
$$


To determine the duration of the project with the time for the completion of jobs being undefined, the Project Evaluation and Review Technique (PERT) is used.

The expected duration of the operation $t_{\exp }$ is calculated as follows:

$$
t_{\text {exp }}=\frac{t_{o p t}+4 t_{m . p .}+t_{p e s}}{6}
$$

where $t_{\text {opt }}$ is the minimum possible (optimistic) time for the completion of the operation;

$t_{\text {pes }}$ is the maximum possible (pessimistic) duration;

$\mathrm{t}_{\mathrm{m} . \mathrm{p} .}$ is the most probable duration of the operation.

To assess the range of deviations from the obtained quantity, the dispersion of executing operations is calculated:

$$
\delta_{t}^{2}=\left(\frac{t_{p e s}-t_{\text {opt }}}{6}\right)^{2}
$$

For setting initial values to conduct PERT analysis, expert and analogue assessment methods and parametric assessment (the division of a fixed volume of jobs by resources engaged) are employed.

The fourth stage of network planning is the allocation of resources earmarked for the implementation of the project, which is effected in the following order:

1. Working out a forecast of the need for resources;

2. Identifying the "peaks" in the use of resources, i.e. periods when there occurs either a resource deficit or resource downtime;

3. Updating the project schedule.

One ought to clearly define the criteria for resource allocation. For instance, such an indicator can come as the resource use coefficient, which reflects the maximum possible volume of resources engaged.

$\mathrm{K}_{\text {used res. }}=\mathrm{Q}_{\text {used }} / \mathrm{Q}_{\text {avail }}(5)$,

where:

$\mathrm{K}_{\text {used res. }}$ is the resource use coefficient;

$\mathrm{Q}_{\text {used }}$ is the volume of used resources;

$\mathrm{Q}_{\text {avail }}$ is the total quantity of available resources.

There are a number of methods used for resolving the resource allocation objective, including dynamic programming, heuristic methods, etc.

The Cost Management Plan. The process of developing the cost management plan presupposes that assessment should be effected for each operation within the frame of the Content Plan.

The total cost of the project includes:

1. The cost of tools, materials, personnel training, all that will be engaged in carrying out planned jobs;

2. The cost of the quality of carrying out jobs. For instance, to abide by all GOST standards, we will have to add operations related to checking on the observance of those standards. Since this is not a result of the project but just a requirement for quality, this will be the cost of quality;

3. The Cost of Risks. These are established for each operation separately;

4. Indirect costs - for instance, those associated with leasing the office space, paying electricity bills, and marketing.

All project costs are divided into two types:

- Variable costs, which are all costs associated with the immediate implementation of the project. For instance, materials, salary, etc.

- Fixed costs, which do not change in the course of the implementation of the project, such as monthly rent.

Cost assessment methods are similar to job duration assessment methods. Among them are one-point assessment, "top to bottom" assessment (by analogues), parametric assessment, PERT analysis, as well as an additional methodology - "bottom to top" assessment. 
The "bottom to top" method involves assessing the cost of each operation for each package of jobs, starting from the lowest level with the summing of the cost of all the operations.

The accuracy of cost assessment depends on several factors - the significance of the project for the company, the competence level of the manager and the project team, project requirements, etc. But the following assessment accuracy standards are generally accepted:

- A rough assessment of the "Order of Magnitude", which is the initial assessment of the project declared in the group of project initiation processes; the accuracy is $+/-50 \%$ of the final one;

- An assessment of the Budget, which is provided in the group of planning processes. It varies from $-10 \%$ to $+25 \%$ relative to the final cost of the project;

- A Clear Assessment, which is made as the project is being implemented, i.e. given after the start of the implementation of the project. The accuracy is $+/-10 \%$ of the final one.

Thus, as soon as the cost of each type of jobs has been determined, one assesses the total cost of the whole project, to which reserves for possible losses are added, i.e. reserves which are defined for each type of jobs inclusive of known risks. Besides, risks which are impossible to determine initially are normally covered with management reserves to the tune of no less than $5 \%$ of the base cost of the project.

It should be noted that identifying risks ahead of time helps avoid issues which can arise in the later stages of the implementation of the project.

Risks can be classified into:

- External, which are any risks which the project team and key interested parties have little control over;

- Internal, which are internal organizational factors: members of the team, a lack of planning, short deadlines, etc.;

- Technical, which are risks related exclusively to the content of the project;

- Unforeseen risks, which are quite a small number of risks; it is recommended that we can include only $10 \%$ of all possible project risks in here.

Risk identification proper is implemented using instruments well-known in the practice of project management brainstorming, the Delphi method, and interviewing. Instruments can also be complemented by the search for major reasons, which is the decomposition of some expected big risk into smaller, more easily assessable ones (for instance, the risk of a unit breaking down can be divided into the risks of its separate parts breaking down). Another instrument worthy of mention is Documentation Analysis, which implies the analysis of theme-based publications, accumulated knowledge, and other documentation external to the project, which helps identify additional risks.

An effective instrument for the qualitative assessment of risks is the composite Probability and Impact matric (Figure 2).

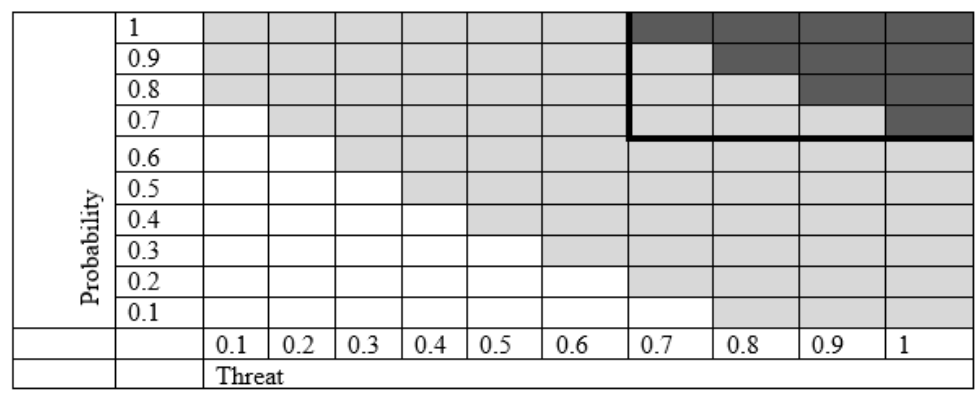

Figure 2. A probability and impact matrix

In the above matrix, the high risk zone is shaded dark, the medium risk zone is shown in grey, and the low risk level zones are colored white. The thick line running from 0.7 to 1 designates the tolerance zone.

After drawing up the matrix, we need to assess all risks based on two parameters - the probability of risk arising and threats the risk entails. Normally, assessment is carried out by an expert in the field, but we also can use PERT analysis as an instrument for assessment. Thanks to these assessments, each risk will characterize the level 
of a threat it is fraught with, and it will be expressed in the probability of risk arising and a threat coming from the risk.

The quantitative assessment of risks helps give a more materialized assessment of the probability of damage in case of a risk event occurring. Possible material losses from risk are calculated via the formula:

$$
\mathrm{EMV}=\mathrm{P} * \mathrm{I}
$$

where $\mathrm{P}$ is the probability of risk arising;

I is material damage to be caused by risk if it arises.

It should be noted that it is not always possible to assess damage with absolute accuracy, in which case an approximate assessment can be considered sufficient.

The total cost of the project, including reserves for possible losses and management reserves, is the project budget, which is the base for making decisions on funding the project.

Funding the project is one of the major focus areas in cost management. It ensures resolving key objectives:

- Ensuring the flow of investment needed for the timely implementation of project jobs inclusive of temporal and financial limitations;

- Reducing the financial costs and risks of the project through the synchronization of investment flows and tax planning.

Large-scale development programs are normally funded through engaged sources, such as the issuance of shares, the issuance of bonds, project financing, leasing, etc.

\section{Results}

The result of work done on planning the project is the development of a list of operations needed to fulfill the content of jobs. This list can have any format and contain any auxiliary information. The list can contain certain control points, which can be established both by the project team and stockholders.

The result of the development of the baseline project schedule is the establishment of the most probable time for the completion of each operation and the duration of the project as a whole. An example of a project schedule with the use of PERT analysis is provided in Table 1.

Table 1. PERT analysis results

\begin{tabular}{|c|c|c|c|c|c|c|c|}
\hline List of jobs & $\mathrm{P}$ & M & $\mathrm{O}$ & $\begin{array}{l}\text { Expected } \\
\text { Duration of } \\
\text { Operatio, } \\
\text { EDO }\end{array}$ & $\begin{array}{c}\text { Standard } \\
\text { Deviation } \\
\text { of } \\
\text { Operation }\end{array}$ & $\begin{array}{l}\text { Minimum time for } \\
\text { completion of job }\end{array}$ & $\begin{array}{l}\text { Maximum time } \\
\text { for completion of } \\
\text { job }\end{array}$ \\
\hline Development of project & 26 & 29 & 35 & 30 & 2.25 & 27 & 32 \\
\hline Purchase of equipment & 6 & 8 & 13 & 9 & 1.75 & 7 & 10 \\
\hline Installation of equipment & 27 & 30 & 33 & 30 & 1.50 & 29 & 32 \\
\hline $\begin{array}{c}\text { Installation of } \\
\text { video-surveillance systems }\end{array}$ & 3 & 5 & 7 & 5 & 1.00 & 4 & 6 \\
\hline Connection to power supply & 70 & 160 & 190 & 150 & 30.00 & 120 & 180 \\
\hline $\begin{array}{l}\text { Connection to water supply and } \\
\text { sewerage service }\end{array}$ & 31 & 65 & 70 & 60 & 9.75 & 50 & 70 \\
\hline $\begin{array}{c}\text { Obtaining permit from } \\
\text { Committee for Architecture }\end{array}$ & 21 & 31 & 36 & 30 & 3.75 & 26 & 34 \\
\hline $\begin{array}{c}\text { Obtaining permits from Fire } \\
\text { Department }\end{array}$ & 31 & 28 & 35 & 30 & 1.00 & 29 & 31 \\
\hline $\begin{array}{l}\text { Obtaining permit from } \\
\text { Department of Environmental } \\
\text { Protection }\end{array}$ & 30 & 60 & 90 & 60 & 15.00 & 45 & 75 \\
\hline
\end{tabular}

The end-result of planning due dates is the calendar plan for the project (Table 2). 
Table 2. A sample of the calendar plan for the project

\begin{tabular}{|c|c|c|c|}
\hline Jobs & $\begin{array}{l}\text { Duration, } \\
\text { days }\end{array}$ & Start date & Finish Date \\
\hline 1. Development of project & 30 & 04.06 .2013 & 03.07 .2013 \\
\hline 2. Paying for and having equipment delivered & 9 & 04.07 .2013 & 12.07 .2013 \\
\hline $\begin{array}{l}\text { 3. Installation of equipment, start-up and commissioning, } \\
\text { personnel training }\end{array}$ & 30 & 03.08 .2013 & 01.09 .2013 \\
\hline 4. Installation of video surveillance systems & 5 & 18.03 .2014 & 22.03 .2014 \\
\hline 5. Connection to power supply & 150 & 20.08 .2013 & 16.01 .2014 \\
\hline 6. Connection to water supply and sewerage system & 60 & 17.01.2014 & 17.03 .2014 \\
\hline 7. Obtaining permit from Committee for Architecture & 30 & 04.07 .2013 & 02.08 .2013 \\
\hline 8. Obtaining permits from Fire Department & 30 & 18.03.2014 & 16.04 .2014 \\
\hline $\begin{array}{l}\text { 9. Obtaining permit from Department of Environmental } \\
\text { Protection }\end{array}$ & 60 & 18.03 .2014 & 16.05 .2014 \\
\hline
\end{tabular}

As a result of allocating resources by the packages of jobs, the project group gets the optimum variant of the schedule, the simplest and most demonstrative form of presenting which is a chart constructed based on the method developed by American engineer H. Gantt (Figure 3).

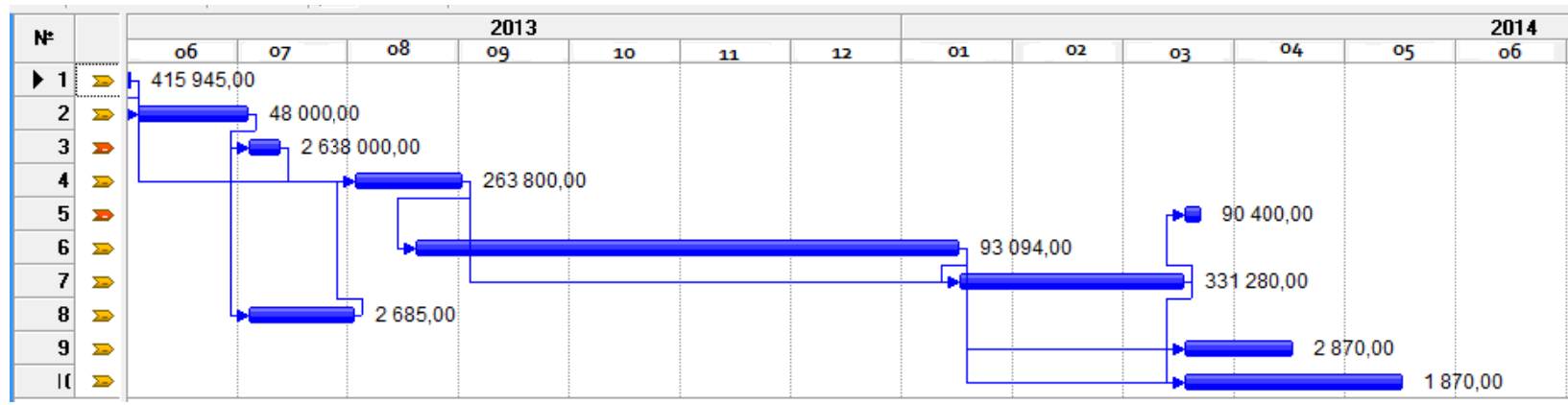

Figure 3. A sample of the Gantt chart

Next, one carries out the quantitative and qualitative assessment of project risks. Once the identification of risks is done, one has to end up with a document that cites all identified risks. Then one ranks risks by the degree of significance and conducts the assessment of the probability of a risk event occurring.

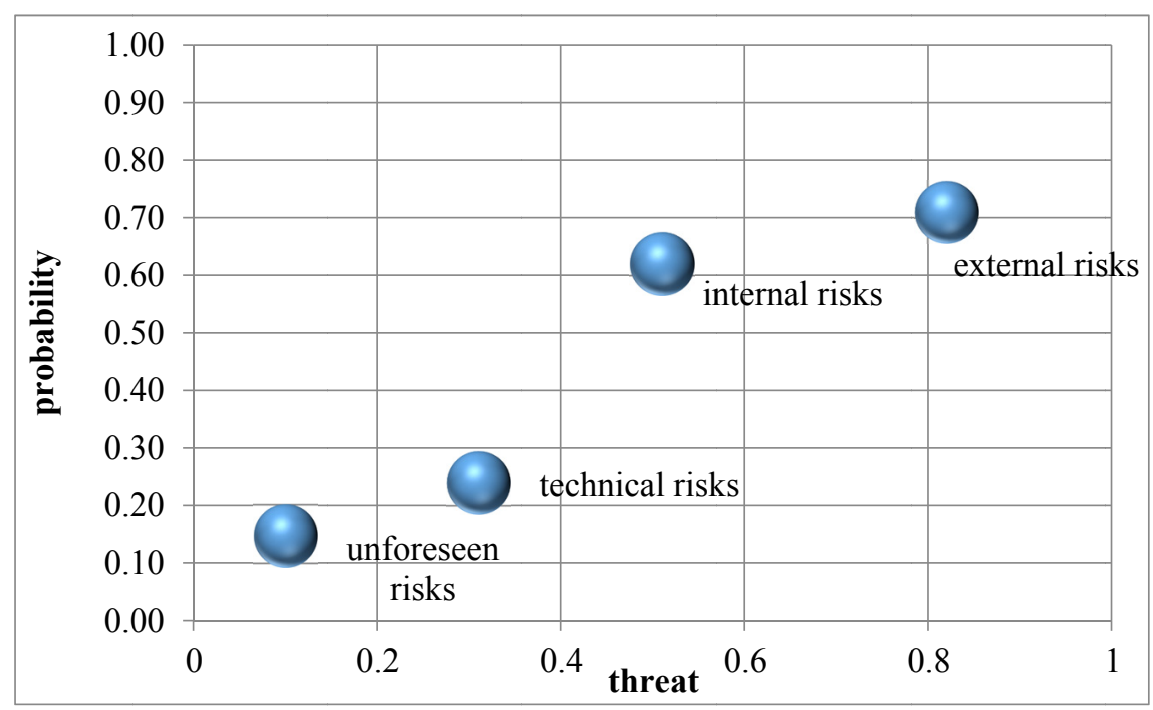

Figure 4. An enlarged project risk map 
As a result of the process of qualitative assessment of risks, each risk will have an assessment, which will help put together a future strategy for interacting with it. In addition to an assessment of each risk separately, the project group will have an aggregate assessment of project risk, based on which there can be implemented the re-planning of the project with a view to reducing risk associated with implementing the project or the company can refuse to implement the project altogether. After the assessments, one can order risks by the assessment made, which facilitates better perception. This updated list will help understand which risks require additional quantitative analysis and which require working out measures for preventing them (or in case of positive risk, stimulating the event).

The results of qualitative risk analysis are provided in the form of the risk map, a sample of which is illustrated in Figure 4.

Not all risks in the project undergo quantitative assessment. For instance, one can establish in the risk management plan that quantitative assessment should cover risks with a risk occurrence and threat probability indicator of more than 9; for those with an indicator of 6 , a response plan should be worked out; and one can just observe risks with an indicator of less than 3.

The resulting document of the cost management plan is the project budget (Table 3).

Table 3. A sample of the project budget, rub

\begin{tabular}{ccccccc}
\hline & Jun.13 & 3 q. 2013 & 4 q. 2013 & 1 q. 2014 & 2 q. 2014 & Total \\
\hline Cumulative direct costs & & & & 722685 & 736724 & 1459409 \\
Cumulative fixed costs & 58990 & 179257 & 234701 & 344189 & 350875 & 1168012 \\
Taxes & & 1416 & 4313 & 70504 & 59002 & 135235 \\
Asset acquisition costs & & 2638000 & & 90400 & & 2728400 \\
Other costs in preparation period & 463945 & 304458 & 55121 & 335101 & 919 & 1159544 \\
Total costs & 522935 & 3123131 & 294135 & 1562879 & 1147520 & 6650600 \\
possible loss reserve & 62752 & 374776 & 35296 & 187545 & 137702 & 798072 \\
management reserve & 26147 & 156157 & 14707 & 78144 & 57376 & 332530 \\
Necessary financial resources, total & 611834 & 3654063 & 344138 & 1828568 & 1342598 & 7781202 \\
\hline
\end{tabular}

Along with the creation of the Project Budget, the project balance replenishment schedule can also be a result of the process of managing costs (Figure 5).

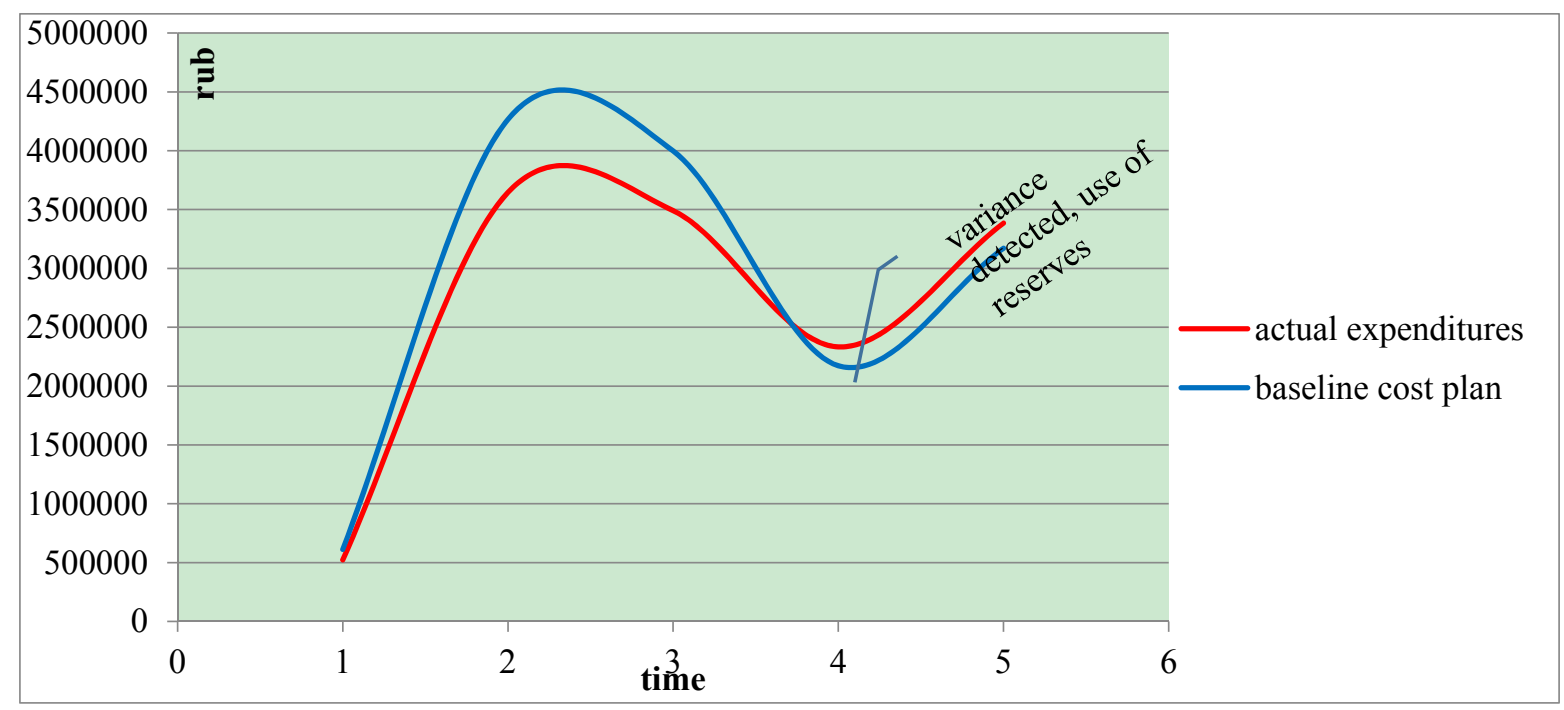

Figure 5. A project balance replenishment schedule

The above graph, apart from planned investment, provides the use of reserves, as well as changes made to the project due to exceeding the limits of the baseline cost plan. 
In the course of managing the implementation of the project, the primary objective of management is to conduct a proper and timely assessment of actual parameters of jobs and compare them with target indicators.

The primary action of the process of managing the implementation of projects is the constant measurement of the project's current state relative to the target one. One more action that has to be fulfilled is looking for the source of problems and trying to remediate it. It is also recommended that one drop the project if it is apparent that its implementation (in particular, within constricted time limits) is impossible.

\section{Discussion}

Despite the fact that over the course of the entire $20^{\text {th }}$ century various scientific schools in Russia had been engaged in working out specific methods and instruments, project management within the frame of implementing large-scale development programs started to develop in Russia quite late. The modern stage in the development of methods and means for project management, within the frame of which several scientific-theoretical strands have come into being, began in the 1980s and has gone on to this day.

A major contribution to the development of scientific methods for project management has been made by S.P. Nikanorov, who is one of the country's first developers of network planning and management systems. The essence of S.P Nikanorov's strand of conceptual design is in that, using a specialized mathematical apparatus, one is enabled to formalize the description of subject fields of any degree of complexity (Nikanorov, 2008).

A considerable contribution to the scientific study of issues in project management has been made by V.I. Voropayev. In 2005, the scientist developed a systemic project management model that enables specialists to structure knowledge, functions, processes, procedures, etc. in the area of project management, define objectives for all the participants, come up with a sequence of resolving them and effective technological interrelations, and interact based on terminology adopted. The author has also developed a complex of mathematical management models aimed at boosting the efficacy of project work and ensuring the actualization of the corresponding competencies of the executive and the project team in various conditions (Voropayev, 2014).

The theory of active systems has been developed in the works of D.A. Novikov, wherein the author provides a rationale for the expediency of the use of mathematical models for boosting the efficiency of operation. The author has developed a management activity methodology that deals with systemic analysis in the logic of modern design-technological types of organizational culture (Novikov, 2011).

Solutions to optimizing cost programs have been examined in the works of V.N. Burkov. The author has developed a methodology that enables one to determine the state of the program by several goals (criteria) based on an integrated assessment system (Burkov \& Burkova, 2014).

The works of V.M. Anshin are dedicated to examining issues in managing the project portfolio, developing project analysis and investment methodologies, and streamlining project implementation technology as part of sustainable development efforts (Anshin, 2013).

The development of scientific-methodological approaches to actualizing the project management system based on the standards of the organization and optimization of business processes and a balanced system of indicators has found reflection in the works of G.L. Tsipes and A.S. Tovba (Tsipes \& Tovb, 2014).

Thus, on the whole, modern Russian scientific-methodological works in the area of project management are characterized by a wide use of the entire spectrum of project management methods and means aimed at resolving topical modern objectives, such as managing projects in the setting of sustainable development, activating and developing human potential, and attaining long-term success.

At the same time, despite the availability of systemic analysis and project management methodologies developed by national specialists, the quality of existing project planning and control processes remains unsatisfactory in many Russian companies, major issues including failure to meet project deadlines, financial discipline violations, ineffective resource management, etc.

\section{Conclusion}

The methodology provided in this article is aimed at streamlining the system of resource planning and formation of the budget of company development projects.

Unfortunately, it should be noted that in Russia, in the project development stage, they create only a baseline schedule and a partial baseline cost fulfillment plan. Our methodology presupposes the mandatory development of three fundamental elements of the project implementation baseline plan: the content plan, the baseline schedule, and the cost management plan. Going forward, having these plans in place will make it possible to 
assess the efficacy of work done by the project team and the project executive, the efficacy of processes, draw proper conclusions and make relevant adjustments to not just the project but the work of the entire company.

At the same time, we should note the existing limitations to the use of this methodology, such as:

- The company's lack of specialists in the area of project management, who match the standards of project managers and possess necessary professional knowledge;

- A lack of special programming solutions on the automation of the project management system. Without the use of means of automating project activity, it is impossible to ensure the necessary level of promptness, accuracy, and fullness of information on the state of the project, which is crucial to making proper managerial decisions in implementing large-scale development programs;

- Labor intensity and a lack of credible information on damage in conducting a quantitative assessment of risks. There is an unspoken rule that characterizes the quality of conducted identification of risks - if the number of risks is less than a hundred; it means that not enough risks have been identified. Practice shows that the per-unit share of calculated risks, i.e. risks which have undergone quantitative assessment, is no more than $10 \%$ of the total number of identified risks.

Besides, further effort is required for the development of methodological solutions in the area of substantiating financial decisions made, i.e. decisions on the rational structure and cost of instruments used for funding the project.

\section{References}

Amason, A. C. (2011). Strategic Management: From Theory to Practice. London: Routledge.

Anshin, V. M. (2013). Project Management inclusive of the Concept of Sustainable Development. In Scientific Studies and Design Efforts. Rossiyskiy Zhurnal Upravleniya Proyektami, 2, 3-15.

Binner, H. (2010). Managing Organizations and Production: From Functional to Process Management (p. 21). Moscow: Alpina Publisher.

Blokhina, T. K., Bykova, O. N., \& Yermolova, T. K. (2014). Economics and Management of Innovation Organizations (p. 44). Moscow: Prospekt.

Burkov, V. N., \& Burkova, I. V. (2014). A Method of Network Programming in Managing Target Programs. Avtomatika i Telemekhanika, 3, 73-86.

Dvorakova, L., \& Zborkova, J. (2014). Integration of Sustainable Development at Enterprise Level. Procedia Engineering, 69, 686-695.

Fidelman, G. N. (2012). Management of Systems: How do You Begin the Path of Toyota? (p. 114). Moscow: Alpina Publisher.

He, L., Chaudhary, N., \& Jarvis, S. A. (2014). Developing Security-Aware Resource Management Strategies for Workflows. Future Generation Computer Systems, September, 61-68. http://dx.doi.org/10.1016/j.future.2013.09.030

Illarionov, A., \& Klimenko, E. (2013). The Project Portfolio: An Instrument for the Strategic Management of the Company (p. 9). Moscow: Alpina Publisher..

Kaplan, R. S., \& Norton, D. P. (2008). The Execution Premium: Linking Strategy to Operations for Competitive Advantage (1st ed.). Harvard Business School Publishing Corporation, Boston.

Lappe, M., \& Spang, K. (2014). Investments in Project Management are Profitable: A Case Study-based Analysis of the Relationship between the Costs and Benefits of Project Management. International Journal of Project Management, 603-612. http://dx.doi.org/10.1016/j.ijproman.2013.10.005

Litvak, B. G. (2011). The Science of Management: Theory and Practice (p. 7). Moscow: Delo.

Mir, F. A., \& Pinnington, A. H. (2014). Exploring the Value of Project Management: Linking Project Management Performance and Project Success. International Journal of Project Management, February, 202-217. http://dx.doi.org/10.1016/j.ijproman.2013.05.012

Nikanorov, S. P. (2008). The Technology of Conceptual Design. Moscow: Contsept.

Novikov, D. A. (2011). The Methodology of Management. Moscow: Librokom.

Serra, C. E. M., \& Kunc, M. (2014). Benefits Realisation Management and Its Influence on Project Success and on the Execution of Business Strategies. International Journal of Project Management. 
http://dx.doi.org/10.1016/j.ijproman.2014.03.011

Shimasaki, C. (2014). Company Growth Stages and the Value of Corporate Culture. In Biotechnology Entrepreneurship. Starting, Managing, and Leading Biotech Companies (PhD thesis). http://dx.doi.org/10.1016/B978-0-12-404730-3.00027-0

Tsipes, G. L., \& Tovb, A. S. (2014). Projects and Project Management in a Modern Company. Moscow: Olimp-Biznes.

Voropayev, V. I. (2014). Mathematical Management Models for the Executive and the Project Management Team. Upravleniye Proyektami i Programmami, 1.

Zhang, F., Rio, M., Allais, R., Zwolinski, P., Carrillo, T. R., Roucoules, L., Mercier-Laurent, E., \& Buclet. N. (2013). Toward a Systemic Navigation Framework to Integrate Sustainable Development into the Company. Journal of cleaner Production, 54, 199-214. http://dx.doi.org/10.1016/j.jclepro.2013.03.054

\section{Copyrights}

Copyright for this article is retained by the author(s), with first publication rights granted to the journal.

This is an open-access article distributed under the terms and conditions of the Creative Commons Attribution license (http://creativecommons.org/licenses/by/3.0/). 